\title{
DEVELOPING THE CASE FOR ENHANCED LANDFILL MINING IN THE UK
}

\author{
Stuart T. Wagland *, Frederic Coulon and Luisa Canopoli \\ School of Water, Energy and Environment, Cranfield University, Bedfordshire, MK43 OAL, United Kingdom
}
Article Info:
Received:
21 March 2018
Revised:
17 November 2018
Accepted:
7 December 2018
Available online:
7 February 2019
Keywords:
Enhanced landfill mining
Waste composition
Landfill chemistry
Resource recovery
Secondary raw materials

\begin{abstract}
Across the UK there are around 22,000 landfills sites, suggesting a significant opportunity for recovering value from previously discarded materials. Enhanced landfill mining (ELFM) has been identified as a concept to recover value from landfills through optimized valorization of the resources extracted. This approach, including waste-to-energy (WtE), waste-to-material (WtM) and waste-to-land (WtL) options can also assist in addressing critical and secondary raw material demands and scarcity. However, to date, there is still limited evidence on this potential. In this paper, the results of 9 UK landfill sites characterization and feasibility studies for ELFM are presented. Waste characterisation from 9 landfill sites located in the UK was carried out. Overall 36 core drills and 118 unique waste samples were analysed. High volumes of fines (soil-like) organic material were observed across all samples and significant levels of valuable metals were observed in this fraction. Previous work had determined significant aluminium and copper are contained in the soil-like fines fraction, which does not include the separate metals fraction (i.e. aluminium cans, copper wires etc). At one site the combustible fraction was assessed as a potential refuse-derived fuel [RDF]. Typically, $10-40 \%$ by weight of the samples at this site were 'combustible', with an average gross calorific value of $12.9 \mathrm{MJ} / \mathrm{kg}$. Plastics extracted from the sites are contaminated and degraded, therefore further work is required to understand the extent of degradation and to assess available options upcycle these materials.
\end{abstract}

\section{INTRODUCTION}

Steady raw materials supply is essential for the UK and EU economy and increasingly under pressure to sustain the businesses and industries demand (Rockström et al., 2009). The supply of raw materials is not only a matter of availability of primary but also secondary raw materials (SRM) (Dino et al., 2016; European Commission, 2017). As such, we need to consider both the scarcity and raising prices of raw materials and the waste management policies aiming at reducing the environmental and health impacts of waste. Recent research has demonstrated that landfill sites can offer a high potential of primary and secondary raw materials [SRM] (Dino et al., 2016) rather than just representing contaminated land that needs remediation (Ortner et al., 2014). Across Europe there are around 500,000 landfill sites (EURELCO, 2016) and around 22,000 historic landfill sites in the UK, of which $90 \%$ have been closed before 1996 (EA, 2015).

Mining landfill solely for SRM or critical raw materials [CRM] is not expected to be financially viable given the extent of the recovery operations involved (Gutiérrez-Gutiérrez et al., 2015). However, concepts such as 'enhanced landfill mining' (Jones et al., 2013) which provides an integrated valorization of landfilled waste streams as materials (Waste-to-Material) and energy (Waste-to-Energy), using innovative transformation technologies and respecting the most stringent social and ecological criteria has the potential to minimize costs through the recovery of multiple commodities and allowing the recovery of valuable land.

While traditional landfill mining has a long history, enhanced landfill mining (ELFM) has come into focus only recently (Jones et al., 2013). ELFM aims at providing optimized valorization of different types of materials extracted from landfill sites and increased energy recovery from waste, aiming to reduce the amount of re-buried waste to almost zero. Furthermore, ELFM projects aim to mitigate greenhouse emissions from landfill sites and landfill mining activities to the atmosphere. To achieve this, various technologies are developed to make waste streams usable for different valorization techniques.

Different options exist for recovery including Waste-to-Material (WtM), Waste-to-Energy (WtE) and Waste-to-Land (WtL) (Jones et al., 2013; OVAM, 2013; Van Passel et al., 2013). Besides WtM and WtE, (Van Passel et al., 2013) also considers WtL, the creation of space at the 
location of the landfill site, as well as allocation of new land use to the remediated landfill site. Furthermore, in ELFM concept, resource management which is defined as "the temporary storage of waste with a view to a later valorization and use of this waste" is taken into account (OVAM, 2013). In most cases of traditional landfill mining, recycling and recovery of materials are only of secondary importance as the main drivers being landfill capacity increase or land clearance for urban development (Ford et al., 2013). This has resulted in a standstill development of specialized mining technologies for ELFM (Ford et al., 2013).

It has been previously reported that recovered materials from landfill sites could provide high economic revenues - the value will depend on the amount and quality of the recovered fractions and the market (Jones et al., 2013; Van Passel et al., 2013). However, the amount of waste that could potentially be recovered depends mainly on the physical and chemical conditions of the landfill site and the efficiency of equipment and technology used (Rosendal, 2009). According to the World Resource Foundation (Strange, 1998), purity of the excavated waste fractions can vary between $70 \%$ and $90 \%$. In this context, purity refers to the level of contamination and the level of target material (i.e. non-target material would make up $10-30 \%$ of a specific recovered stream). A high amount of plastics can be found in landfills. Joseph et al. (2007) concluded that it is not viable to recycle plastics due to highly diminished quality. Quaghebeur et al. (2013) reaches the same conclusion. The authors state that excavated plastic, textile, paper/cardboard and wood do not have the required quality for recycling and reintegration in the production market. Therefore, the best valorization route for these types of waste is widely considered to be $\mathrm{WtE}$ in the absence of other viable means of recovering value from these materials.

As the concept of ELFM gains traction, it is critical to further our understanding of the wastes contained within the landfills across Europe in order to develop robust plans for undertaking large-scale operations and to identify the technology, and technology development, needs.

This paper compiles the data from 9 landfill sites sampled across the UK, investigating the physical composition of each site, determining metal content and the potential of using landfill-derived materials as refuse-derived fuels [RDF].

\section{MATERIALS AND METHODS}

\subsection{Sample collection}

Samples were taken from landfill sites across the UK, predominantly handling municipal waste and general waste from commercial premises. 36 core samples were extracted from 9 landfill sites located across the United Kingdom, which were then divided into 118 samples based on the depths, for example the 22 samples from Site 8 is $1 \mathrm{x}$ core drill divided into 1 metre increments (up to 22 metres). The core samples were taken from drilling activities using a $450 \mathrm{~mm}$ diameter auger (drill barrel). The samples used in this work are summarized in Table 1; the age and status of the sites is shown, however the specific age of each core and sample is not possible to specify accurately. Two separate test sites were investigated at Site 4 which were wet and dry areas of the site and are referred to as $4 a$ and $4 \mathrm{~b}$, respectively. The depths of the samples typically ranged from 0-22 metres, with many samples being in the range of 6-18 metres.

\subsection{Composition analysis and characterisation}

The samples were collected from the landfill sites, sealed in double-layered bags and stored at $4^{\circ} \mathrm{C}$ until analysis. The samples were hand-sorted Waste was screened and separated by hand into plastics, paper and fines as defined by Quaghebeur et al. (2013) (degraded garden and food materials), textiles, glass and metal. Waste composition was reported as a percentage contribution of total weight. Dry matter (DM) or Total solids (TS) and Volatile Solids (VS) of the paper and fines were determined in triplicate following the procedure British Standard methods (British Standards Institute, 2011a, 2011b, 2011c).

In addition to the DM, TS and VS content, the calorific values of the combustible fractions were determined in accordance with the standard method (British Standards Institute, 2011d) using a Parr 6400 Isoperibol bomb calorimeter.

The composition was determined for all sites. The calorific values were measured for all samples (combustibles

TABLE 1: Overview of sites and samples used.

\begin{tabular}{|c|c|c|c|c|c|}
\hline Site $n^{\circ}$. & Site status & Age of site (as of 2018) & Total sample count & No. cores & Maximum sample depth (m) \\
\hline 1 & Closed & 38 & 6 & 1 & 10 \\
\hline 2 & Open & 26 & 6 & 2 & $\begin{array}{l}26 \\
30\end{array}$ \\
\hline 3 & Closed & 24 & 10 & 6 & 20 \\
\hline $4 a$ & Closed & 22 & 13 & 2 & 19 \\
\hline $4 b$ & Closed & 22 & 10 & 5 & 25 \\
\hline 5 & Open & 10 & 27 & 5 & 13 \\
\hline 6 & Closed & 38 & 10 & 5 & 19 \\
\hline 7 & Closed & 20 & 10 & 7 & 19 \\
\hline 8 & Open & 20 & 22 & 1 & 22 \\
\hline 9 & Closed & 28 & 4 & 2 & 20 \\
\hline
\end{tabular}


only) extracted from site 8 . The combustible fractions were separated, dried overnight and ground to $<10 \mathrm{~mm}$ using a Retsch SM 2000 shredder.

\subsection{Metal content of waste fractions}

The metal content was determined as described by Gutiérrez-Gutiérrez et al. (2015). To achieve the highest quantity of the extracted metals, samples were submitted to nitric acid digestion followed by a digestion with aqua regia $\left(\mathrm{HNO}_{3}+\mathrm{HCl}\right.$ in a ratio of $\left.1: 3\right)$, as it was not technically possible to use HF to digest the samples. Briefly, for the nitric acid digestion, $0.5 \mathrm{~g}$ of sample was mixed with $8 \mathrm{ml}$ of $\mathrm{HNO}_{3}$ (70\%, 1.42 density, Fisher Scientific) in Teflon tubes and left overnight. The samples were placed in a microwave digester (Multiwave 3000, Anton Paar) for 45 minutes at $800 \mathrm{~W}$. The mixtures were then filtered $(150 \mathrm{~mm}$, hardened low ash paper, Fisher Scientific) and the remaining liquid was diluted to $100 \mathrm{ml}$ with distilled water and retained for analysis. The filter paper and residue was then dried for 2 hours at $105^{\circ} \mathrm{C}$ and placed into a digestion tube with 6 $\mathrm{ml}$ of $\mathrm{HCl}(37 \%, 1.18$ density, Fisher Scientific) and $2 \mathrm{ml}$ of $\mathrm{HNO}_{3}$. The mixture was subjected to microwave irradiation at $800 \mathrm{~W}$ for 45 minutes. The solution was filtered and the liquid diluted to $100 \mathrm{ml}$ and retained for analysis.

The retained solutions were analysed for metal content using inductively coupled plasma mass spectrometry (ICPMS) (Elan 9000 Perkin-Elmer SCIEX) using several certified standard solutions for calibration.

The organic/fines fraction from sites 1-4 was analysed for rare earth elements and critical/valuable metals (Gutiérrez-Gutiérrez et al., 2015). To further investigate the distribution of metals, along with heavy metal elements, all fractions of waste extracted from site 9 were analysed.

\section{RESULTS AND DISCUSSION}

The results of the compositional analysis, as an average for each site, is illustrated in Figure 1. The soil-like or- ganic material (fines) ranges between $30-74 \%(w / w)$, which is expected due to the relatively high proportion of food waste in household and general commercial wastes, along with the common practice of applying a daily soil cover to landfills during operation. The soil-like fraction had a similar consistency to soil, however is a mixture of the soil cover and humic material formed from the biodegradation of organic wastes. This finding is in agreement with previous studies on the characterisation of excavated waste samples (Garcia et al., 2016; Mor et al., 2006; Quaghebeur et al., 2013) where the composition of fine materials increases with depth (Frank et al., 2017).

Plastics were prominent in many samples, in particular across sites 2, 5, 6 and 7, with the plastic content ranging from $8.5 \%$ in site 9 to $44 \%$ in site 5. Quaghebeur et al (2013) observed a plastic content of up to $25 \%$, so the waste extracted from sites 2, 5, 6 and 7 are higher than expected. This could be due to the age of the material and extent of degradation (i.e. reduction of the biodegradable proportion), or could be due to the waste types deposited; the sites predominantly accepted MSW, however some commercial and industrial wastes were disposed of, which is typically lower in organic content at the time of disposal.

The presence of such a significant organic/fines fraction suggests that for any enhanced landfill mining operation to be viable, this material would need to be separated and managed. Soil and complex organic matter are able to bind to metals, such as those mobilised in leachate material. This phenomenon was explored (Gutiérrez-Gutiérrez et al., 2015), with the results of this analysis from sites 1-4 presented in Figure 2 (rare earth elements and selected critical metals) and Table $2(\mathrm{Cu}, \mathrm{Ag}, \mathrm{Au}$ and $\mathrm{Al})$.

The quantities of rare earth elements (REE) and other critical materials in relatively low concentrations suggest that mining for these materials alone would not be economically viable (Gutiérrez-Gutiérrez et al., 2015). However, when recovered as part of a large enhanced landfill

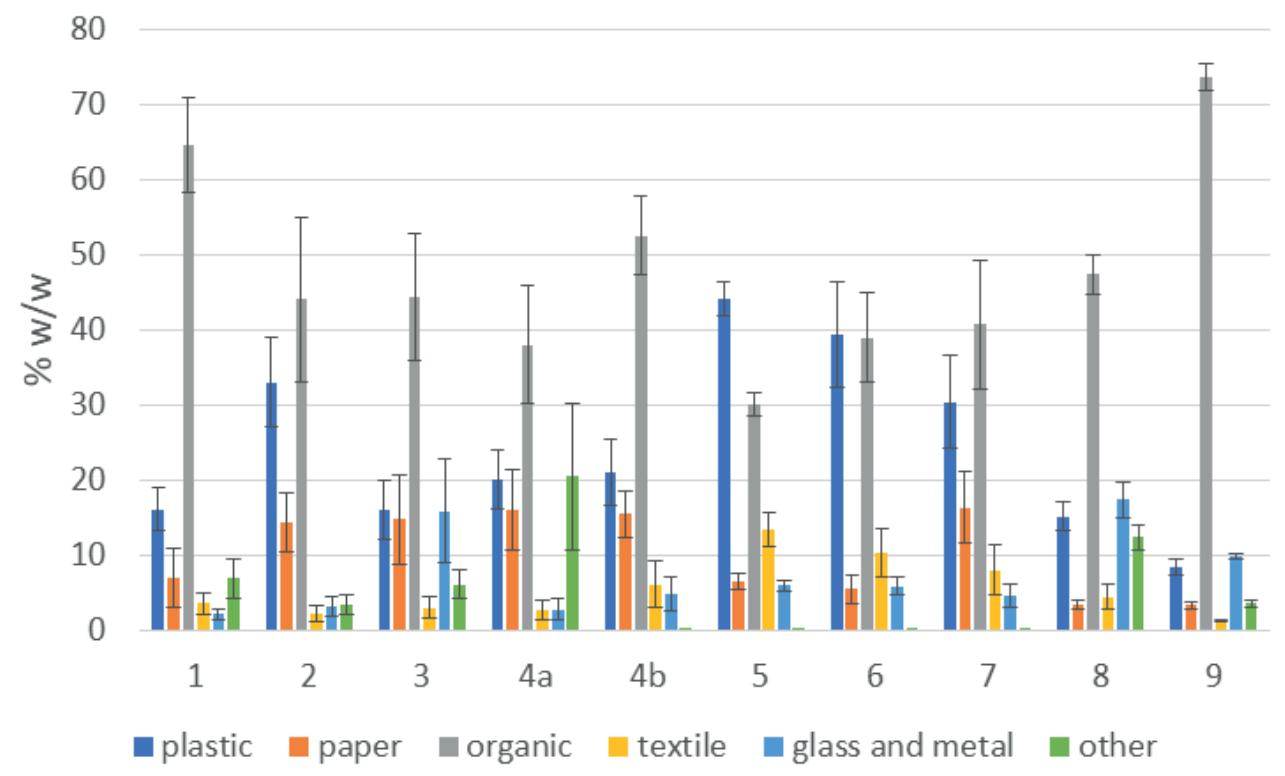

FIGURE 1: Average waste composition of sites 1-9 (error bars shown as standard error of the mean). 


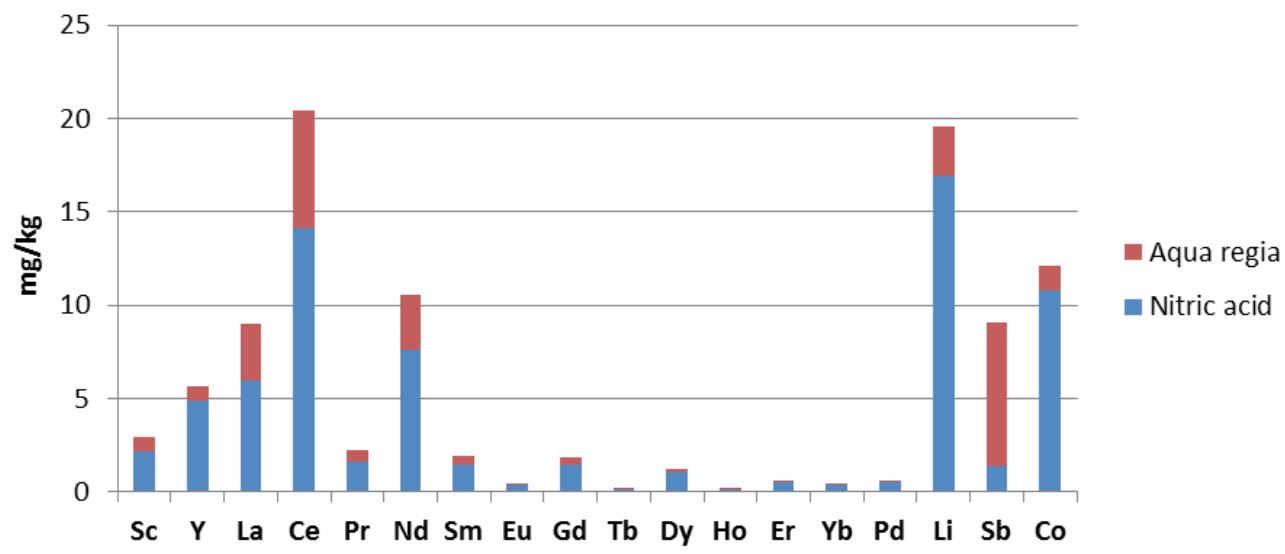

FIGURE 2: Rare earth elements and selected critical metal content of the fines (soil-like organic) fraction from sites 1-4.

mining undertaking then the recovery could be viable. This study focuses on the total metals present, however further work would be required to understand the recoverability of each metal. The $\mathrm{Cu}$ and $\mathrm{Al}$ concentrations measured are significant, and across the $4 \mathrm{x}$ sites analysed this represents a potentially viable resource of these metals. The combined value of aluminium and copper from within the fines fraction across the four sites is around $\$ 400$ million (Gutiérrez-Gutiérrez et al., 2015), which is assuming complete recovery.Complete recovery wouldn't be expected in any recovery operation, therefore these values provide perspective of the scale of the metals. Due to the varied composition of waste within landfills, excavation solely for the purpose of these metals would be a significant technical challenge, in addition to the commercial viability previously mentioned.

To expand the work described by Gutiérrez-Gutiérrez et al. (2015) a further site was characterised in detail. Each fraction from site 9 was analysed for the REE and critical metals, the results of which are shown in Table 3a-c.

The REE observed in the fines fraction are closely aligned to the values in sites $1-4$, however the $\mathrm{Cu}$ and $\mathrm{Al}$ values are lower, with the reasons for this requiring further research. Of the heavy metals $\mathrm{Cr}, \mathrm{Pb}$ and $\mathrm{Zn}$ are most abundant, with the $\mathrm{Cr}$ content being significantly higher than values reported for non-landfilled wastes and MSW incinerator residues (Jung et al., 2004; Øygard et al., 2004). Chromium is, therefore, likely to chemically mobile in landfills through leachate movement arising from hazardous materials such as paints, batteries and chemical/industrial residues. However the values observed in wood materials suggests that the wood fraction separated in this study was treated with copper chromium arsenate [CCA], previous a widely-used wood preservative. The presence of such high $\mathrm{Cr}$ levels does suggest that any enhanced landfill mining operation would need to take into consideration environmental and human health risks posed by $\mathrm{Cr}$, and other hazardous elements present.

For the samples from Site 8, the average gross calorific value [GCV] of the combustible fraction measured with the calorimeter is $18.2 \pm 5.7 \mathrm{MJ} / \mathrm{kg}$ (GCV, dry). Figure 3 illustrates the net calorific value [NCV] on dry basis for each sample in comparison with the composition of combustible materials. On an as-received basis, the GCV and NCV for the combustible fraction were $12.9 \mathrm{MJ} / \mathrm{kg}$ and $11.0 \mathrm{MJ} /$ $\mathrm{kg}$ respectively.

The samples analysed here provide an indication of the contents of such landfill sites, however are not absolute values due to the volume of the landfill sites in comparison with the number of samples analysed. Obtaining representative samples from a whole landfill site presents a significant challenge, and further work is required to consider the statistically valid number of samples required. Further work could also involve innovative whole-site characterisation techniques, including electromagnetic measurements (Bobe et al., 2018).

Research groups have investigated the use of excavated landfill material for use as RDF, or solid recovered fuel [SRF], with challenges mostly arising due to the need to separate significant volumes of fines. Wolfsberger and Hollen (2014) concluded that the separation process was not efficient due to the $42 \%$ moisture and $69 \%$ fines contents in the waste material (Wolfsberger and Hollen, 2014). Results for the current project show a lower moisture content $(26,3 \%)$ and a reduced percentage of fines (47.4\%). Thus, the process' efficiency could be expected to be higher, al-

TABLE 2: Content of $\mathrm{Cu}, \mathrm{Ag}, \mathrm{Au}$ and $\mathrm{Al}$ (in $\mathrm{mg} / \mathrm{kg}$ ) for sites 1-4.

\begin{tabular}{|c|c|c|c|c|}
\hline \multirow{2}{*}{ Metal } & \multicolumn{4}{|c|}{ Average content (mg/kg) } \\
\hline & Site 1 & Site 2 & Site 3 & Site 4 \\
\hline $\mathrm{Cu}$ & 1,076 & 1,027 & 2,595 & 1,830 \\
\hline $\mathrm{Ag}$ & 2.26 & 2.77 & 3.63 & 5.02 \\
\hline $\mathrm{Au}$ & 0.18 & 0.13 & 0.16 & 0.05 \\
\hline $\mathrm{Al}$ & 17,274 & 12,357 & 12,594 & 12,079 \\
\hline
\end{tabular}


TABLE 3: Critical metals (a), light REE (b) and heavy metal (c) content of waste fractions from site 9. All numbers presented as mg/kg.

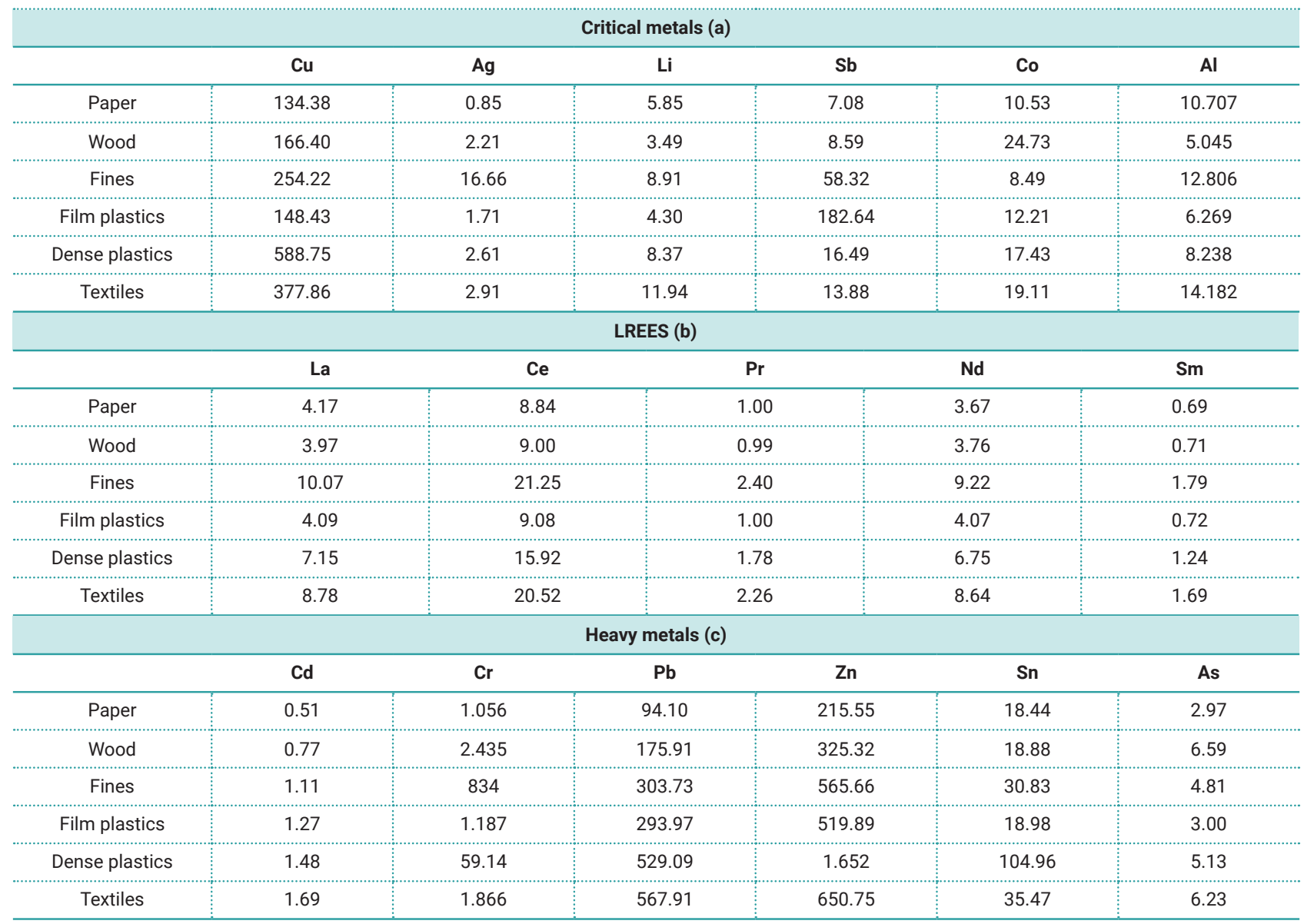

though an industrial scale testing would have to be undertaken.

On the other hand, the process described by Jones et al. (2013) could be viable for RDF recovery from the present landfill, though it would also need to be evaluated in large scale. The fines fraction, in this case, was lower (39\%) than in the work presented here. In short, RDF production is strongly influenced by the amount of fines present in the waste. Extensive sieving and separation of the fines are vital in order to obtain high quality RDF.

The relatively high proportion of plastics in landfill contributes to the CV, which is comparable to SRF produced from fresh MSW (Velis et al., 2012; Wagland et al., 2011). As the plastics are likely to be degraded and/or contami-

\section{Calorific Value}

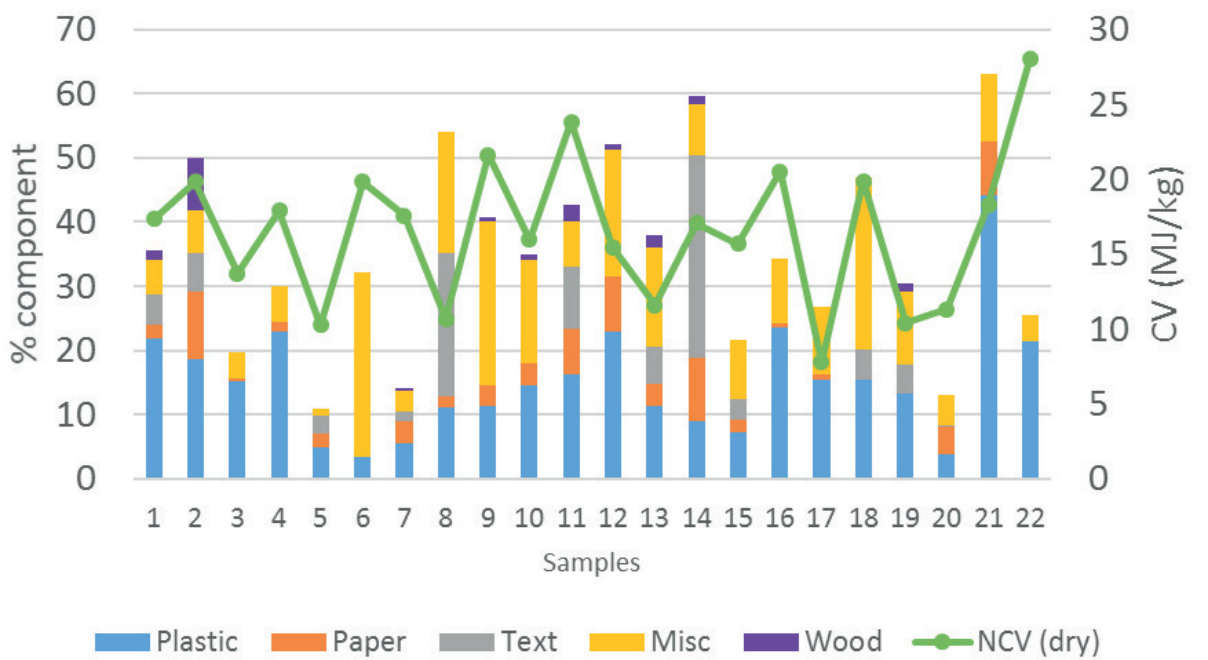

FIGURE 3: Combustible fraction and composition of site 8 with the NCV (dry), MJ/kg, for each sample. 
nated through long-term exposure to leachate and landfill gas, it is not likely that all plastics recovered from landfill can be recycled conventionally (Joseph et al., 2007). Therefore, advanced options such as pyrolysis and gasification of plastics could upcycle these materials into chemicals and liquid fuels; this is a topic which has not been fully explored and so further work is required.

In summary, RDF production from enhanced landfill mining operations is one potential outlet, however successful valorisation of landfilled material is likely to comprise a flexible approach utilising options such as the recovery of recyclable materials (metals, for example), upcycling of plastics, refining of the fines material and the production of RDF.

\section{CONCLUSIONS}

The findings have highlighted that the waste composition varied across sites and between samples, however the percentage of fines (soil-like organics) is consistently high in comparison to other materials. This volume of fines presents a challenge in managing materials excavated from ex-situ landfill mining operations however the results presented here, and in previous studies, suggests that this material also contains valuable secondary raw materials.

Direct recycling of remaining plastics/paper/textiles might not be economically viable due to contamination and degradation. However options for managing these resources include the use of the combustible fraction as RDF or as a feedstock for advanced thermal conversion, potentially to produce valuable chemicals and/or liquid fuels.

\section{ACKNOWLEDGEMENTS}

This research has received funding from the European Union's Horizon 2020 research and innovation programme under Grant Agreement No 641988 [SMART GROUND].

To The authors are also grateful to students on the MSc Waste and Resource Management, MSc Environmental Engineering and MSc Energy from Waste for the 2016/17 academic year at Cranfield University, who contributed to aspects of some of the site characterisation and physicochemical analysis.

\section{REFERENCES}

Bobe, C., Van Der Vijver, E., Van Meirvenne, M. 2018. Exploring the potential of electromagnetic surface measurements for the characterisation of industrial landfills. Enhanced Landfill Mining IV symposium. 2018.

British Standards Institute, 2011a. BS EN 15414-3:2011 Solid recovered fuels - Determination of moisture content using the oven dry method. Part 3: Moisture in general analysis sample. London, UK.

British Standards Institute, 2011b. BS EN 15402:2011, Solid recovered fuels. Determination of the content of volatile matter.

British Standards Institute, 2011c. BS EN 15403:2011, Solid recovered fuels. Determination of ash content.

British Standards Institute, 2011d. BS EN 15403:2011 Solid recovered fuels - Methods for the determination of Calorific Value.

Dino, G.A., Rossetti, P., Biglia, G., Coulon, F., Gomes, D., Wagland, S., Luste, S., Särkkä, H., Ver, C., Delafeld, M., Pizza, A., 2016. SMART GROUND Project: SMART Data Collection and Integration Platform to Enhance Availability and Accessibility of Data and Information in the EU Territory on Secondary Raw Materials. Energy Procedia 97, 15-22. doi:10.1016/j.egypro.2016.10.010
EURELCO, 2016. Landfills in Europe infographic [WWW Document]. URL https://docs.wixstatic.com/ugd/f593b3_62af11921f9e404c8e511f4925c78bd7.pdf (accessed 7.2.17).

European Commission, 2017. Raw materials [WWW Document]. URL http://ec.europa.eu/environment/green-growth/raw-materials/index_en.htm (accessed 7.2.17).

Ford, S., Warren, K., Lorton, C., Smithers, R., Read, A., Hudgins, M., 2013. Feasibility and Viability of Landfill Mining and Reclamation in Scotland. Final Report, Zero Waste Scotland, http//www. zerowastescotland. org. uk.

Frank, R.R., Cipullo, S., Garcia, J., Davies, S., Wagland, S.T., Villa, R., Trois, C., Coulon, F., 2017. Compositional and physicochemical changes in waste materials and biogas production across 7 landfill sites in UK. Waste Manag. 63, 11-17. doi:10.1016/j.wasman.2016.08.026

Frank, R.R., Davies, S., Wagland, S.T., Villa, R., Trois, C., Coulon, F., 2016. Evaluating leachate recirculation with cellulase addition to enhance waste biostabilisation and landfill gas production. Waste Manag. 55, 61-70. doi:10.1016/j.wasman.2016.06.038

Garcia, J., Davies, S., Villa, R., Gomes, D.M., Coulon, F., Wagland, S.T., 2016. Compositional analysis of excavated landfill samples and the determination of residual biogas potential of the organic fraction. Waste Manag. 55, 336-344. doi:10.1016/j.wasman.2016.06.003

Gutiérrez-Gutiérrez, S.C., Coulon, F., Jiang, Y., Wagland, S., 2015. Rare earth elements and critical metal content of extracted landfilled material and potential recovery opportunities. Waste Manag. 42, 128-136. doi:10.1016/j.wasman.2015.04.024

Jones, P.T., Geysen, D., Tielemans, Y., Van Passel, S., Pontikes, Y., Blanpain, B., Quaghebeur, M., Hoekstra, N., 2013. Enhanced Landfill Mining in view of multiple resource recovery: a critical review. J. Clean. Prod. 55, 45-55. doi:10.1016/j.jclepro.2012.05.021

Joseph, K., Esakku, S., Nagendran, R., 2007. Mining of compost from dumpsites and bioreactor landfills. Int. J. Environ. Technol. Manag. 7, 317-325.

Jung, C., Matsuto, T., Tanaka, N., Okada, T., 2004. Metal distribution in incineration residues of municipal solid waste (MSW) in Japan. Waste Manag. 24, 381-391. doi:10.1016/S0956-053X(03)00137-5

Mor, S., Ravindra, K., De Visscher, A., Dahiya, R.P., Chandra, A., 2006. Municipal solid waste characterization and its assessment for potential methane generation: A case study. Sci. Total Environ. 371, $1-10$.

OVAM, 2013. Determination of the potential of Landfill Mining and the need for remediation of landfills in Flanders.

Øygard, J.K., Mage, A., Gjengedal, E., 2004. Estimation of the mass-balance of selected metals in four sanitary landfills in Western Norway, with emphasis on the heavy metal content of the deposited waste and the leachate. Water Res. 38, 2851-2858. doi:10.1016/j. watres.2004.03.036

Quaghebeur, M., Laenen, B., Geysen, D., Nielsen, P., Pontikes, Y., Van Gerven, T., Spooren, J., 2013. Characterization of landfilled materials: screening of the enhanced landfill mining potential. J. Clean. Prod. 55, 72-83. doi:10.1016/j.jclepro.2012.06.012

Rockström, J., Steffen, W.L., Noone, K., Persson, Å., Chapin III, F.S. Lambin, E., Lenton, T.M., Scheffer, M., Folke, C., Schellnhuber, H.J., 2009. Planetary boundaries: exploring the safe operating space for humanity.

Rosendal, R.M., 2009. Landfill Mining process, feasibility, economy, benefits and limitations (JOUR), Danish association of municipal waste management companies.

Strange, K., 1998. Landfill Mining. World Resour. Found. Heath House, High Street, Tonbridge, Kent TN9 (kit@ wrf. org. uk). Available from http//www. cbvcp. com/columbiasd/techpage [accessed May 2003].

Van Passel, S., Dubois, M., Eyckmans, J., de Gheldere, S., Ang, F., Tom Jones, P., Van Acker, K., 2013. The economics of enhanced landfill mining: private and societal performance drivers. J. Clean. Prod. 55, 92-102. doi:10.1016/j.jclepro.2012.03.024

Velis, C., Wagland, S., Longhurst, P., Robson, B., Sinfield, K., Wise, S., Pollard, S., 2012. Solid Recovered Fuel: Influence of Waste Stream Composition and Processing on Chlorine Content and Fuel Quality. Environ. Sci. Technol. 46, 1923-1931. doi:10.1021/es2035653

Wagland, S.T., Kilgallon, P., Coveney, R., Garg, A., Smith, R., Longhurst, P.J., Pollard, S.J.T., Simms, N., 2011. Comparison of coal/solid recovered fuel (SRF) with coal/refuse derived fuel (RDF) in a fluidised bed reactor. Waste Manag. 31, 1176-1183.

Wolfsberger, T., Hollen, D., 2014. Landfill Mining - Case Study: Characterization and treatment of excavated waste from Austrian sanitary landfill sites and estimation of the resource potential. ISWA, Leoben, Austria. 